\title{
Aproximación a las ideas políticas y éticas de Karl Popper
}

\author{
Luis Armando González ${ }^{1}$
}

Recibido en noviembre de 2015, aceptado en marzo de 2016

\begin{abstract}
Pero un hombre que critica la democracia y las instituciones democráticas no debe ser, forzosamente, su enemigo... La crítica de Sócrates era de naturaleza democrática, más aún, era ese tipo de crítica que constituye la vida misma de la democracia.
\end{abstract}

Karl Popper

\begin{abstract}
Resumen
En estas notas se exponen algunas ideas políticas y éticas de Popper a partir de tres libros suyos: Después de la sociedad abierta, La sociedad abierta y sus enemigos, y La responsabilidad de vivir. Se ensaya apenas una aproximación somera a su pensamiento político y ético, con el ánimo de rescatar, desde escritos significativos, nociones que permiten no sólo entender mejor a uno de los filósofos más relevantes del siglo XX, sino apuntalar mejor nociones que en el presente han perdido espesor y rigor, especialmente en el ámbito de la ética.
\end{abstract}

\section{Palabras claves}

Karl Popper, ideas políticas, ética, Hayek, neoliberalismo, autoliberación.

\begin{abstract}
In these notes some political and ethical ideas of Popper are exposed from three of his books: After the open society, Open society and its enemies, and The responsibility to live. a cursory approach to its political and ethical thought, with the aim of rescuing from significant writings, notions that allow not only better understand one of the most important philosophers of the twentieth century but underpin better notions tested only in the present have lost thickness and rigor, especially in the field of ethics.
\end{abstract}

\section{Keywords}

Karl Popper, political ideas, ethics, Hayek, neoliberalism, self-liberation. 


\section{Introducción}

Del filósofo Karl R. Popper (1902-1994) se han dicho y se dicen muchas cosas, algunas correctas pero otras con poco fundamento. Ha tenido denostadores acerbos y también apólogos acríticos. Obviamente, también conocedores a fondo de su obra, críticos bien informados y discípulos creativos. Lo común en los dos primeros bandos es la lectura superficial de la obra de Popper o, peor aún, una interpretación a partir de lo que otros creyeron encontrar en sus libros; esto último es muy común en quienes, en lugar de tomarse la molestia de leer los textos de un autor, se conforman con lo que terceros dicen de él, con lo cual pierden la oportunidad de formarse una visión propia de sus ideas.

Al respecto, en estos tiempos que está en boga en distintos ambientes hacer de la ética una exigencia impuesta por el Estado y, en ese sentido, sometida a criterios de penalización también emanados del Estado, es pertinente escuchar lo que una voz autorizada tiene que decir sobre tales pretensiones. Y también es útil prestar atención a lo que este autor tiene que decirnos sobre las responsabilidades estatales ante la desigualdad, la injusticia y el crimen.

Así pues, en este texto se busca reivindicar a un autor importante, del cual se suelen decir cosas no siempre atinadas, pero también rescatar ideas suyas que pueden enriquecer el debate público nacional en los siempre polémicos ámbitos de la política y de la ética.

\section{Popper: ¿neoliberal y hayekiano?}

En los años ochenta, circulaba la tesis -que resuena de vez en cuando- de que Popper era un positivista lógico. No pocos repetimos esa tesis -que era una condena a Popper, por supuesto- sin siquiera haber leído un libro completo suyo. Con suerte, la adscripción estaba respaldada en alguna cita suelta de sus escritos, pero por lo general la única base era la opinión de algún profesor respetado, en cuyo juicio se confiaba. Si se hubiera tenido conocimiento de la obra de Popper no sólo se habría sabido de su no pertenencia al Círculo de Viena -manifestada expresamente por él en distintas ocasiones-, sino de su crítica radical, rigurosa y permanente del positivismo lógico, especialmente del inductivismo epistemológico en que este se sostiene ${ }^{2}$. Ciertamente, el positivismo lógico ha recibido las más variadas críticas, pero la de Popper es la más contundente.

2. El autor de este ensayo calificó equivocadamente a Popper de ser un "positivista refinado", en un artículo publicado en 1997 que, en realidad, tuvo una primera versión en la década anterior, quizás en 1986. Cfr., L. A. González, "Notas en torno al debate explicación comprensión". Realidad, No. 60,1997 . Posteriormente, quien esto escribe hizo un intento de recuperar la crítica de Popper al positivismo lógico, con una lectura más meditada de sus escritos. Cfr., L. A. González, "Epistemología y racionalismo crítico (Los griegos y Karl Popper)". Realidad, mayo-junio de 2001, pp. 273-300. 
A la acusación de ser un positivista lógico se añadió otra, más drástica pero igualmente infundada: la de ser un neoliberal, con todos los aditamentos que se suelen asociar al neoliberalismo: individualismo posesivo (en la línea de Macpherson), defensa irrestricta del libre mercado, renuncia al bien común y abandono a su suerte de quienes no pueden ocupar un lugar en un mercado gobernado exclusivamente por el "dejar hacer, dejar pasar". Al leer los escritos políticos y sociales de Popper no se encuentra una base firme para considerarlo un neoliberal. Su crítica a Marx o su crítica al utopismo no son suficientes para ello.

Es difícil que sea un neoliberal alguien que piensa que "cada generación de hombres, y por tanto también los seres vivos, tienen una exigencia; quizás no será tanto una exigencia de ser felices (...) sino una exigencia de que no lo hagan desgraciado ahí donde se pueda evitar. Tienen derecho a que, si sufren, se les ofrezca toda la ayuda posible". ${ }^{3} 0$ quien piensa que "deberíamos procurar ocuparnos de los problemas reales más acuciantes como, por ejemplo, ayudar a los débiles y a los enfermos, y a quienes sufren injusticia, evitar el desempleo, igualar las oportunidades y evitar el crimen internacional, eso es, la extorsión y la guerra incitados por tiranos irresponsables y megalómanos". ${ }^{4}$

Como se verá después, hay una huella de la ética cristiana presente en el pensamiento social de Popper que quizás permita entender mejor su opción por una "ingeniería social fragmentaria". También hay en sus planteamientos acentos socialdemócratas -que quedaron vivos desde su militancia socialdemócrata de juventud- y keynesianos que impiden convertirlo en un vocero del neoliberalismo. Quizás lo más cercano a la realidad sea definirlo como un liberal socialista. En una carta de Rudolf Carnap (del 6 de enero de 1947), en respuesta a la pregunta de si es socialista, Popper - a la vez que elude dar una respuesta directa a Carnap- enlista las convicciones que comparte con los socialistas, al tiempo que expone los aspectos en los que se distancia de ellos. Y concluye la carta del siguiente modo:

Creo que las filosofías políticas del socialismo y el liberalismo que hemos heredado del siglo XIX son un poco demasiado simples y al mismo tiempo demasiado ingenuas. Comparto plenamente (...) la convicción de los liberales de que lo más importante en política es la libertad. Pero estoy asimismo convencido que la libertad no puede salvarse sin mejorar la justicia distributiva, es decir, si no se acrecienta la igualdad económica. Esta es la razón por la que creo que debemos renunciar a las creencias dogmáticas y semirreligiosas en este ámbito y esforzarnos por alcanzar una actitud más racional. $Y$ esto es algo que liberales y socialistas podrían compartir. ${ }^{5}$

3. K. R. Popper, “Ideal y realidad en sociedad (1940)". En Después de la sociedad abierta. Barcelona, Paidós, 2010, p. 100.

4. Ibíd., p. 107.

5. “Popper a Carnap, 6 de enero de 1947”. Ibíd., pp. 154-157. 
Hay que decir aquí que, si bien la presunta adscripción neoliberal de Popper ha sido difundida por sus denostadores más furibundos, varios de sus apologistas han dado motivos para ello, con su pretensión de convertir a Popper en un adalid del neoliberalismo, mediante la identificación -injustificada- de la "sociedad abierta" (sobre la que Popper tiene una propuesta) con el capitalismo de mercado neoliberal. Definitivamente, la concepción popperiana de la sociedad abierta no es equivalente a sociedad capitalista: "por 'sociedad abierta' no entiendo -dice- un 'sistema social' definido, sino fundamentalmente una sociedad tolerante, una sociedad en la que son toleradas las peculiaridades del individuo, y más en concreto, en la que el pensamiento crítico y hasta la crítica de los tabúes son tolerados, una sociedad en la que, por tanto, podemos ser artífices de nuestro propio destino y no sus profetas". ${ }^{6} \mathrm{Y}$ en un escrito posterior, apunta: "una sociedad, una manera de vivir juntos, basada en la idea no de tolerar a un hombre y sus convicciones, sino de respetarlo en su persona y convicciones, es el tipo de sociedad que yo llamo una sociedad abierta". ${ }^{7}$

Ni siquiera, contra lo que muchos creen, Mario Vargas Llosa acepta esa identificación, que otros autores, menos eruditos que el peruano, dan por establecida. Dice Vargas Llosa:

el liberalismo de Karl Popper es profundamente progresista porque está imbuido de una voluntad de justicia que a veces se halla ausente en quienes cifran el destino de la libertad sólo en la existencia de mercados libres, olvidando que éstos, por sí solos, terminan, según la metáfora de Isaiah Berlin, permitiendo que los lobos se coman a todos los corderos. La libertad económica, que Popper defendió, debía complementarse, a través de una educación pública de alto nivel y diversas iniciativas de orden social, como una vida cultural intensa y accesible al mayor número, a fin de crear una igualdad de oportunidades que impidiera, en cada generación, la creación de privilegios heredados, algo que le pareció siempre tan nefasto como los dogmas religiosos y el espíritu tribal. ${ }^{8}$

En esa misma línea de ver en Popper a un baluarte del neoliberalismo, están los que, más recientemente, quieren ver en él a un hayekiano a ultranza. Tampoco se sostiene esa concepción ni en la obra epistemológica ni en el pensamiento social y político de Popper. De su amistad con Hayek - sin duda muy fuerte- no se sigue que Popper fuera su seguidor, su discípulo o el fundamentador de las tesis económicas de aquél. Lo que sí es llamativo es que una carta dirigida a Rudolf Carnap (25 de abril de 1946) Popper se refiere a la fama de "reaccionario" de Hayek y trata de suavizar esa fama, acercándolo a su propia postura:

6. "La teoría del totalitarismo. Una conferencia sobre La sociedad abierta (1946)". En Ibíd., p. 191.

7. "La sociedad abierta y el Estado Democrático (1963)". En Ibíd., p. 305.

8. M. Vargas Llosa, "El joven Popper”. El País, 9 de septiembre de 2012. 
Debo responder en concreto - dice a Carnap-a una consideración que usted hace en su carta. Se trata de la observación sobre Hayek y su fama de 'reaccionario'. Sin lugar a dudas, Hayek trata de mostrar los peligros del 'socialismo' y, en especial, del intento utopista de hacer que la sociedad funcione sin mercado. Pero no es desde luego un adalid del capitalismo sin límites. Al contrario, insiste en la necesidad de un sistema de 'seguridad social', de una política anticíclica, etc. Que todos o más bien casi todos los izquierdistas lo consideran un reaccionario es, por desgracia, lamentablemente cierto... El agradecimiento que manifiesto en mi libro se refiere a su ayuda práctica más que a su influencia; pero, desde que terminé mi libro, he tenido la oportunidad de leer a Hayek (...), y sólo puedo decir que he aprendido muchísimo. ${ }^{9}$

Cualquiera puede concluir que ese "he aprendido muchísimo" estaría indicando una dependencia de Popper respecto de Hayek, pero eso es forzar las cosas. Más adelante, en la misma carta, Popper comenta a Carnap que "unos pocos izquierdistas aquí en Inglaterra, se hallan en la misma situación, como por ejemplo, Barbara Wootton, que ha respondido a Hayek con seriedad y ha reconocido el gran provecho que ha sacado de sus argumentos". ${ }^{10} \mathrm{Si}$ se compara este juicio de Popper para con Hayek, y su juicio para con Marx es evidente que para este último, aunque la crítica es más radical, el reconocimiento es mayor. En una carta a Carnap (31 de marzo de 1943), en respuesta a una observación que este le hace sobre su tratamiento de Marx, en el libro Falsos profetas: Platón, Hegel, Marx, que luego se convertirá en La sociedad abierta y sus enemigos, Popper responde así a Carnap:

Respecto a sus consideraciones sobre mi manera de tratar a Marx, el libro le hace plena justicia, en lo que se refiere tanto a sus logros teóricos como a sus intenciones. Pero también lo critica. No necesitamos un Gran Sistema de filosofía social. La crítica que hago de Marx es cuidadosa y detallada... ciertamente no soy el más indicado para decir que soy 'objetivo'. Sólo puedo decir que, pese a mi actitud crítica, tengo una debilidad por Marx y lo admiro como pensador. Asimismo, en mi libro expreso claramente que debo muchísimo a la influencia de Marx. Al mismo tiempo trato de demostrar que el 'historicismo' de Marx, es decir, su creencia fundamental en un curso predeterminado de la historia, conduce al misticismo y se alza como un escollo en el camino de una 'ingeniería social gradualista' ecuánime y racional”. ${ }^{11}$

9. “Popper a Carnap, 25 de abril de 1946”, en Ibíd., pp. 150-151.

10. Ibíd., p. 151.

11. “Popper a Carnap, 31 de marzo de 1943”. Ibíd., p. 138. 


\section{La unidad indisoluble de moral y política}

Así las cosas, no se sostienen las apreciaciones que hacen de Popper un neoliberal o un hayekiano, y por supuesto tampoco un marxista. Sí tiene más sentido su adscripción a una especie de liberal socialismo, con mayor énfasis en la filiación liberal que en la socialista. Es una conjugación difícil la que realiza Popper, pero es su apuesta por los individuos humanos la que prevalece frente a la realidad del Estado. "Esto supone - dice- que nuestro interés por la política o la sociedad se basa por entero en nuestro interés por los individuos humanos, nuestra preocupación por ayudarlos y nuestra responsabilidad con ellos". ${ }^{12}$ En la relación existente entre individuos y Estado, en la que la balanza se suele inclinar del lado del segundo, Popper elige poner en primer lugar a los individuos: "a todas luces se trata de un individualismo, esto es, un individualismo altruista, sin duda, que conduce a la exigencia de que el Estado exista en aras de los individuos y no -como exigía Platón al igual que los fascistas- el individuo en aras del Estado". ${ }^{13}$

No se trata de un Estado al servicio exclusivo de un individuo poseedor, sino de individuo altruista, es decir, de un individuo no sólo racional sino moralmente responsable. "Este fue en realidad el credo de muchos hombres desde los tiempos de Sócrates. Y es también, creo, la actitud cristiana, y citaré un pasaje que ilustra este individualismo del cristiano extraído de la disertación que pronunció el reverendo Merlin Davies: “Los cristianos -escribe el reverendo Davies- entraron en política con la convicción de que el ser humano, creado por Dios y redimido por Cristo, tiene un valor superior"14. Es ese valor superior del ser humano -que Popper valora como uno de los legados más imperecederos del cristianismo- lo que inspira su liberalismo y su opción por los individuos frente al Estado.

En ese sentido, si la prioridad la tienen los individuos, lo importante no es preguntarse por la naturaleza del Estado, su origen o su destino, sino cuáles son sus funciones y sus obligaciones. Es decir, se trata de hacer un juicio moral en torno al Estado y no una reflexión ontológica sobre el mismo. "En lugar de preguntar, ¿qué es el Estado?, ¿cuál es su verdadera naturaleza?, ¿cuál es su significado real?, o en lugar de preguntar ¿cómo se originó el Estado y cuál es su destino?, deberíamos, creo, preguntar: ¿por qué preferimos vivir en un Estado bien ordenado a vivir sin Estado, es decir, en un estado de anarquía? Este modo de plantear nuestra pregunta nos ayudará a descubrir no la verdadera naturaleza del Estado, sino nuestros deseos, nuestras exigencias morales acerca del Estado". ${ }^{15}$

12. "Hombre moral y sociedad inmoral (1940)". En Ibíd., pp. 112-113.

13. Ibíd., p. 113.

14. Ibíd., p. 112.

15. Ibíd., p. 113. 
Como se verá más adelante, en la visión de Popper, la única moral que existe es la de los individuos; y son estos, por tanto, los que valoran moralmente al Estado, a partir de si cumple o no con las exigencias que tiene frente a ellos. A la manera de Kant, la pregunta que el individuo se hace es la siguiente: ¿qué puedo esperar del Estado? ¿Cuál la exigencia más importante que le planteo? Y responde Popper:

Si formulamos nuestra pregunta de esa manera, la respuesta del cristiano y también del humanitarista o del humanista será que aquello que exijo del Estado es protección, no sólo para mí, sino también para los demás. Exijo protección para mi propia libertad y para la libertad de los demás. No quiero vivir a merced de quien tenga los puños más fuertes o las armas más poderosas. En otras palabras quiero vivir protegido de la agresión de otros hombres. Quiero que se reconozca la diferencia entre agresión y defensa, y que la defensa se sustente en el poder organizado del Estado. Por mi parte estoy perfectamente dispuesto a aceptar que el Estado recorte en algo mi libertad de acción si eso permite obtener a cambio protección para aquella parte de libertad que aún me resta... Pero exijo que no se pierda de vista el propósito fundamental del Estado, me refiero a la protección de esa libertad que no perjudica a los demás ciudadanos. Por lo tanto exijo que el Estado limite la libertad de los ciudadanos de la forma más equitativa posible y no más allá de lo necesario". ${ }^{16}$

Ya lo dijimos: en Popper el énfasis liberal es sumamente fuerte, por encima de los aspectos socialistas que él considera válidos. De ahí el peso decisivo que otorga a la libertad en su consideración de las principales obligaciones del Estado. Pero no se trata de una libertad no sujeta a ninguna restricción por parte del Estado ni tampoco de una libertad no sujeta a ninguna responsabilidad moral y política. El humanismo de Popper y la visión del ser humano que la sostiene permiten comprender mejor su idea de libertad, así como de los límites de la misma. Y también su noción del “Estado proteccionista". El texto siguiente es esclarecedor:

A la concepción del Estado que hemos esbozado aquí se le puede dar el nombre de 'proteccionismo'. El término 'proteccionismo' se ha utilizado a menudo para describir las tendencias que son contrarias a la libertad. Así, el economista entiende por proteccionismo la política de protección de determinados intereses industriales frente a la competencia; y el moralista, la exigencia de que los funcionarios del Estado establezcan una tutela moral sobre la población. Si bien la teoría política que llamo proteccionismo no está relacionada con ninguna de esas tendencias, y aunque en lo fundamental es una teoría liberal, creo que el nombre

16. Ibíd. 
puede utilizarse para indicar que, pese a ser liberal, nada tiene que ver con la política del laissez faire. Liberalismo e intervención del Estado no son cosas opuestas. Al contrario, cualquier tipo de libertad es a todas luces imposible a menos que el Estado la garantice. ${ }^{17}$

De nuevo, la difícil combinación liberal socialista que Popper intentó en repetidas ocasiones en sus escritos. Lo mismo que intentó una síntesis ${ }^{18}$ que recogiera lo mejor de ambas tradiciones en vista a resolver problemas concretos de las personas, tanto en orden a asegurar la libertad (liberalismo) como en orden a reducir las desigualdades socio-económicas y la explotación (socialismo):

...pero podríamos incluso afirmar que la exigencia concreta socialista de que el Estado intervenga para evitar la explotación se puede derivar como una consecuencia del propio credo del liberal. Para el liberal, la protección del ciudadano contra la intimidación y la extorsión es una de las primeras funciones del Estado. Una vez que se acepta la argumentación socialista según la cual el económicamente más fuerte puede amedrentar y extorsionar a otro económicamente más débil, al igual que si usara la intimidación física, el liberal está obligado a admitir que la prevención de semejantes cosas es una función legítima del Estado. ${ }^{19}$

En el intento de síntesis buscado por Popper lo prioritario es la libertad, pero su salvaguarda no obedece a ningún esquema rígido y predeterminado, sino que se trata de una búsqueda no exenta de ambigüedades. Eso es precisamente lo que él reconoce a continuación cuando escribe:

...la cuestión importante y difícil de la limitación de la libertad no se puede solucionar con una fórmula estereotipada. $Y$ es preciso aceptar con entusiasmo que haya siempre casos ambiguos, porque, sin el estímulo de las luchas políticas de ese tipo, la disposición de los ciudadanos a luchar por la libertad pronto desaparecería y, con ella, su libertad. (Considerado bajo este ángulo, el supuesto enfrentamiento entre libertad y seguridad, es decir, una seguridad garantizada por el Estado, resulta una quimera, porque no hay libertad si no se haya garantizada por el Estado. Y, a la inversa, sólo el Estado que es controlado por ciudadanos libres puede ofrecerles una seguridad razonable). ${ }^{20}$

\footnotetext{
17. Ibíd., pp. 114-115.

18. Trabajar por la unión de liberales y socialistas -dice en una carta a Hayek (1946)- "es hoy, sin exagerar, la principal tarea que tenemos todos nosotros". "Unificar a los partidarios del humanitarismo" (1943-1947). En Ibíd., pp. 166-170.

19. "Valores públicos y privados” (¿1946?). En Ibíd., p. 180.

20. Ibíd., p. 115.
} 


\section{Humanismo y moral}

Popper se refiere a su propia postura ética como humanista o humanitarista. Su visión descansa en una prioridad absoluta de la persona y su libertad ante las exigencias de la economía, la política, la religión o la ideología. Es a la luz de la prioridad de la persona que Popper realiza su crítica a cualquier instancia de poder material o espiritual que ahogue a la persona y que la someta a dinámicas que le impidan desarrollarse plenamente. Sobre todo, el humanismo popperiano se alza en contra de esas interpretaciones religiosas e históricas que no sólo niegan la realidad concreta de los individuos, sino que los ven como sometidos a fuerzas (divinas o seculares) que escapan a su control y que hacen de ellos unas marionetas del devenir histórico. La crítica religiosa de Popper es inseparable de su crítica al historicismo, pues ambos niegan la realidad concreta de las personas:

Sostener que Dios -escribe en una clara alusión a Hegel-, se revela a Sí mismo en lo que solemos llamar 'historia', en la historia del crimen internacional y del asesinato en masa, es ciertamente una blasfemia. En efecto, todo cuanto ocurre realmente en el reino de las vidas humanas rara vez se ve afectado por ese cruel y al mismo tiempo pueril asunto. La vida del hombre individual, olvidado y desconocido, sus penas y sus alegrías, su sufrimiento y su muerte, ese es el contenido real de la experiencia humana a lo largo de las edades del mundo. ${ }^{21}$

Tras esa concepción histórica, según la cual Dios manifiesta sus designios a través de los Grandes y Poderosos, lo que hay, dice Popper, es uno de nuestros peores instintos, "el culto idólatra al poder, al éxito, [que] nos ha llevado a creer que es real. ¡Y en esta historia no hecha ya por el hombre sino falseada por el hombre, algunos cristianos se atreven a ver la mano de Dios! ¡Y cuando le imputan sus mezquinas interpretaciones históricas se atreven a decir que comprenden y saben lo que Él quiere!". ${ }^{22}$

Popper hace suyos los planteamientos de Karl Barth - uno de los teólogos protestantes más lúcidos del siglo XX-, especialmente su crítica a cuantos, con petulancia, creen conocer lo que Dios es y sus designios. "Al contrario -dice el teólogo Karl Barth en su Credo-, debemos comenzar admitiendo [...] que todo lo que creemos saber cuando decimos 'Dios' no lo alcanza [o] abarca, sino tan sólo a uno de nuestros ídolos preconcebidos y fabricados por nosotros mismos, ya se trate del 'espíritu', la 'naturaleza', el 'destino' o la 'idea' [...]. Y sin abandonar esta actitud, Barth califica la 'doctrina neoprotestante de la de la revelación de Dios en la historia de 'inadmisible’ y la considera una usurpación de la realeza de Cristo'”. Y añade Popper:

21. “¿Tiene la historia algún significado?” (1940). En Ibíd., p. 121.

22. Ibíd., p. 122. 


\begin{abstract}
Pero, desde el punto de vista cristiano, no es sólo que la arrogancia subyazca a estos intentos; se trata, sobre todo, de una actitud anticristiana. Pues el cristianismo, si algo enseña, es que el éxito no es lo decisivo. 'Cristo padeció bajo el poder de Poncio Pilatos', y vuelvo a citar a Barth: “Cómo entró Poncio Pilatos en el credo? A lo que cabe dar una respuesta sencilla e inmediata: es una cuestión de fecha'. De este modo, la potencia histórica en la época desempeña aquí un papel puramente técnico de indicadora del momento en que ocurrieron estos hechos... Estos hechos sólo fueron los sufrimientos de la vida de Cristo y no sólo de su muerte; y [Barth] nos dice: 'Jesús sufre. Por lo tanto no conquista, no triunfa, no tiene éxito [...]. Nada logró salvo [...] su crucifixión. Lo mismo podría decirse de su relación con su pueblo y con sus discípulos"”. ${ }^{23}$
\end{abstract}

Llama la atención cómo Popper se anticipa, en más de 20 años, a la gran renovación eclesial que será propiciada por el Concilio Vaticano II (1962-1965). Dejando de lado la recuperación que se hace en este Concilio del "misterio de Dios", ${ }^{24}$ la constitución pastoral Gaudium et espes comienza con una declaración que guarda semejanzas extraordinarias con el texto de Popper citado antes y escrito en 1940:

Los gozos y las esperanzas, las tristezas y las angustias de los hombres de nuestro tiempo, sobre todo de los pobres y de cuantos sufren, son a la vez gozos y esperanzas, tristezas y angustias de los discípulos de Cristo. Nada hay verdaderamente humano que no encuentre eco en su corazón. La comunidad cristiana está integrada por hombres que, reunidos en Cristo, son guiados por el Espíritu Santo en su peregrinar hacia el reino del Padre y han recibido la buena nueva de la salvación para comunicarla a todos. La Iglesia por ello se siente íntima y realmente solidaria del género humano y de su historia.

Sin ser un hombre religioso, Popper no sólo aboga por una recuperación de los valores humanos propios del cristianismo, sino que reconoce que las personas

23. Ibíd., pp. 121-123.

24. Cfr., Sólo como ejemplo, se puede leer lo siguiente, en la Constitución dogmática Dei Verbum: "Dispuso Dios en su sabiduría revelarse a Sí mismo y dar a conocer el misterio de su voluntad, mediante el cual los hombres, por medio de Cristo, Verbo encarnado, tienen acceso al Padre en el Espíritu Santo y se hacen consortes de la naturaleza divina. En consecuencia, por esta revelación, Dios invisible habla a los hombres como amigos, movido por su gran amor y mora con ellos, para invitarlos a la comunicación consigo y recibirlos en su compañía. Este plan de la revelación se realiza con hechos y palabras intrínsecamente conexos entre sí, de forma que las obras realizadas por Dios en la historia de la salvación manifiestan y confirman la doctrina y los hechos significados por las palabras, y las palabras, por su parte, proclaman las obras y esclarecen el misterio contenido en ellas. Pero la verdad íntima acerca de Dios y acerca de la salvación humana se nos manifiesta por la revelación en Cristo, que es a un tiempo mediador y plenitud de toda la revelación”. En http:// www.vatican.va/archive/hist_councils/ii_vatican_council/documents/vat-ii_const_19651118_deiverbum_sp.html. 
creen en algo que es más que ellos mismos, lo cual los hace religiosos, lo quieran o no. "Creo -escribe- que todos los hombres, y me incluyo entre ellos, somos religiosos. Todos creemos en algo más y -resulta difícil acertar con las palabras adecuadas- que es más que nosotros mismos. Si bien no quiero fundar ningún tipo de fe, aquello en lo que creemos realmente es en lo que llamo un Tercer Mundo ${ }^{25}$, algo que se halla más allá de nosotros y con lo que podemos interactuar, en el sentido literal de la interacción, a través de lo cual podemos trascendernos a nosotros mismos". ${ }^{26}$

Sin embargo, la opción que se haga por creencias religiosas concretas es, para Popper, una decisión personal; lo mismo que lo es no profesar ninguna fe en particular. En ambas situaciones estamos ante decisiones morales que, en cuanto tales, son responsabilidad exclusiva de las personas, y no imposiciones externas, a las que éstas deban sujetarse.

Esto permite hacer dos consideraciones. La primera es que, en la visión de Popper, el ámbito de la moral no es exclusivo de la religión (o de las religiones). Más aún, "es un gran error identificar la religión con la moralidad por un lado, y, por el otro, la irreligión con la inmoralidad. En efecto, un hombre religioso puede ser inmoral. $Y$ un hombre que afirma no tener religión (como por ejemplo, el gran científico inglés T. H. Huxley) puede ser profundamente moral". ${ }^{27}$

La pretensión de simplificar las cosas de ese modo no sólo se dio en la época en la que Popper escribió su texto “Ciencia y religión" (1940). Ha sido una tentación permanente, sobre todo en situaciones sociales complejas, de conflicto o de erosión de las reglas morales y culturales de convivencia. En los tiempos que corren, hay una ofensiva cultural conservadora y neoconservadora mediante la cual no sólo se busca identificar moral con religión $-\mathrm{y}$, por el lado contrario, no religión con inmoralidad-, sino también alejar lo moral del ámbito de la responsabilidad individual para trasladarlo al ámbito institucional estatal desde el cual se juzgará y sancionarán las faltas morales (o éticas).

Popper fue sumamente crítico de las pretensiones de legislar la moral y de vigilarla y castigar cualquier falta moral desde un tribunal distinto al de la propia conciencia. Tras las huellas de Kant no dudó en suscribir el célebre enunciado kantiano "el cielo estrellado sobre mí, la ley moral en mí" según el cual el único juez de su moralidad debe ser el propio individuo. "No basta -escribecon seguir los mandamientos de una religión o de una autoridad religiosa. No podemos trasladar nuestra responsabilidad moral a los demás. Somos, en última instancia, responsables de nosotros mismos por todo lo que hacemos, también

25. En otros escritos, quizá de forma más apropiada, Popper habla del "Mundo 3", de las creaciones espirituales y culturales, en contraposición al "Mundo 2", de la realidad subjetiva, y al "Mundo 1", de las realidades físicas-materiales.

26. "Ciencia y religión (1940)". En Ibíd., p. 94.

27. "Ciencia y religión (1940)". En Ibíd., p. 91. 
por la religión que adoptamos". ${ }^{28}$

Por ser la moral (o la ética, entendiendo ambos términos como sinónimos ${ }^{29}$ ) un asunto de responsabilidad individual, Popper es sumamente crítico de las tesis que sostienen que el Estado debe preocuparse por la moralidad de las personas, vigilar su moral y asegurar su rectitud, incluso por la vía del castigo. Es decir, nuestro autor se opone a la idea de que la moral de las personas debe ser legislada, pues ello va en detrimento de la autonomía de las personas y, en consecuencia, de la naturaleza misma de la moral. El pasaje que citamos a continuación es esclarecedor al respecto, ya que trata de las exigencias que algunos autores hacen al Estado en materia moral:

Se trata de la exigencia -dice- de que los funcionarios del Estado deben preocuparse por la moralidad de los ciudadanos y utilizar el poder, no tanto para la protección de la libertad de aquéllos, sino para la vigilancia de su vida moral. En otras palabras, es la exigencia de que el reino de la legalidad, es decir, de las normas impuestas por el Estado, se acreciente a expensas del reino de la moralidad propiamente dicha, es decir de las normas no impuestas por el Estado sino a través de nuestras propias decisiones morales. Pero quienes plantean estas exigencias, por lo visto, no advierten que eso significaría poner fin a la responsabilidad moral del individuo y que, por tanto, no mejoraría, sino que destruiría toda moralidad. Sustituiría la responsabilidad personal por los tabúes de la tribu... Contra toda esta actitud, el individualista debe sostener que la moralidad de los Estados - si existe tal cosadebe ser considerablemente inferior a la del ciudadano medio, de modo que resulta mucho más conveniente que los ciudadanos controlen la moralidad del Estado y no a la inversa. Lo que necesitamos y queremos es moralizar la política, no politizar la moral. ${ }^{30}$

En el terreno moral, pues, la responsabilidad personal es insustituible. No se puede obligar a nadie -ni desde el Estado ni desde alguna otra instancia social o cultural- a seguir un comportamiento moral determinado o, en el límite, a ser bueno y recto. Es propio de un esquema medieval (oscurantista y totalitario) imponer criterios, obligaciones y sanciones morales a los individuos desde el Estado. Si una persona es obligada desde el Estado a seguir un cierto comportamiento, el mismo deja de ser moral (o ético) desde el momento que está sujeto a una penalización institucional. Desde un enfoque popperiano, no puede tomarse tan a la ligera el tema de los “tribunales de ética" como dependencias estatales, que sólo recuerdan los tribunales eclesiásticos del medioevo.

\section{Ibíd., p. 91.}

29. En filosofía, se suele distinguir entre ética y moral, siendo la primera una disciplina filosófica, mientras la que segunda el objeto de estudio de la primera. Sin embargo, en el lenguaje cotidiano no se suele hacer esa distinción. Popper tampoco la hace.

30. "Hombre moral y sociedad inmoral (1940)". En Ibíd., pp. 117-118. 
En sentido estricto, no puede haber tribunales de ética (de moral), a menos que se acepte que lo ético-moral es algo impuesto, vigilado y castigado, desde fuera del individuo, y no una opción libre y responsable de éste. Si este es el caso, entonces se tiran por la borda no sólo todas las concepciones morales ilustradas, laicas y humanistas, sino todas las conquistas morales que desde lo griegos, en el siglo $\mathrm{V}$ antes de Cristo, se han venido abriendo paso, en lucha frontal contra quienes siempre han buscado ahogar tanto a la razón como a la capacidad de decisión personales. Es decir, en contra de quienes siempre se han opuesto a que los seres humanos alcancen su mayoría de edad y, apelando al propio tribunal de su conciencia, decidan la vida moral que quieren seguir.

Así las cosas, desde el Estado democrático ${ }^{31}-\mathrm{y}$ por ello, laico- no cabe legislar sobre el ámbito moral, ni sancionar a los ciudadanos por fallas morales (que siempre serán fallas desde ciertas concepciones morales), que son establecidas por personas que, por su parte, han optado por determinadas concepciones morales en detrimento de otras. Si se trata de comportamientos o prácticas anómalos para la sociedad $-\mathrm{y}$ ya contemplados como delitos en los sistemas penales-, no tiene sentido calificarlos de (y tratarlos como) faltas éticas o morales. Como enseñan los teóricos de la ética (por ejemplo, Adolfo Sánchez Vázquez ${ }^{32}$ o J.L.L. Aranguren ${ }^{33}$ ), es, en primer lugar, la propia persona la que deberá juzgarse moralmente a sí misma; y en segundo lugar, lo deberá hacer -si así lo deciden sus miembros- la comunidad social a la que ella pertenece.

Lo mismo que cada comunidad social es la que deberá juzgar la moralidad del Estado, en cuanto conjunto de instancias que tiene una responsabilidad ante la sociedad. Y en este punto, la visión de Popper - su filosofía ética- apunta a una responsabilidad del Estado que no consiste en buscar la felicidad de los ciudadanos o un "bien supremo" cualquiera que sea el contenido positivo que se le dé a éste. Desde su punto de vista, "la lucha contra males concretos que son evitables, como la miseria, que se puede evitar, debería considerarse responsabilidad pública, en tanto que la realización de bienes positivos concretos similares no debería ser considerada una obligación pública". ${ }^{34}$

Propongo - señala más adelante- que hay un gran número de males muy concretos como, por ejemplo, el hambre, el dolor, la humillación, la injusticia, la explotación y otros muchos que los hombres padecen en el momento actual o que han sufrido en el pasado; y que la lucha contra esos males es algo muy bien definido. ${ }^{35}$

31. Por lo cual Popper entiende "un conjunto de instituciones, como por ejemplo una constitución, un derecho civil y un derecho penal, órganos legislativos y ejecutivos, así como el gobierno y las leyes por medio de las cuales [el gobierno] es elegido; los tribunales de justicia, la administración pública, los órganos de sanidad pública, defensa y demás". "La sociedad abierta y el Estado democrático (1963)", Ibíd., p. 309.

32. Cfr., A. Sánchez Vázquez, Ética. Barcelona, Crítica, 1984.

33. J.L.L. Aranguren, Ética. Barcelona, Ediciones Altaya, 1998.

34. "Valores públicos y privados (¿1946?)”. En Ibíd., p. 171.

35. Ibíd., p. 172. 
¿Cuál de esos males privilegiar? El más grave y más concreto, responde Popper. Considero que el deber más urgente es luchar contra el mal mayor y más concreto, y que la urgencia decrece a medida que pasamos a males menores y por supuesto cuando pasamos a bienes positivos. No sé si existe un bien supremo o no (...). Pero si existe, entonces su superación sería, desde mi punto de vista, la cosa menos urgente de la faz de la Tierra. Para mí, en comparación, sería como un lujo. Y la idea, más en particular, de que para la realización del bien supremo vale la pena hacer grandes sacrificios, me parece lisa y llanamente perniciosa. Podemos exigir sacrificios, sobre todo sacrificios en relación con bienes positivos, si son necesarios para luchar contra un mal apremiante concreto. Pero no exigimos sacrificios ni toleramos males concretos como el precio que merece ser pagado por un bien remoto. ${ }^{36}$

Cada sociedad debe determinar, con realismo, honestidad y sensibilidad cuál es el mal más apremiante contra el cual debe luchar no sólo su Estado, sino ella misma. Debe decidir también si el bien remoto por el que se está apostando -dígase la felicidad, la igualdad, la justicia o la democracia ideal- no va en detrimento de la urgencia que reviste atacar el mal mayor que genera sufrimiento, humillación y muerte en el aquí y ahora para sus miembros. Se trata de un asunto no sólo político, sino fundamentalmente ético-moral. Desde el mismo es que se debe juzgar el papel del Estado ante la sociedad; si cumple o no su responsabilidad no ante la consecución de un "bien común" ideal, sino ante la suerte que cotidianamente corren las personas cuando están expuestas a riesgos y amenazas que sólo el Estado (y nadie más) debe contener y aplacar. Quizás el Estado, como todo o en alguna de sus esferas de poder, no cumpla con su responsabilidad política y moral ante los ciudadanos. Quizás el Estado, como un todo o en una de sus partes, falle en su obligación fundamental. En tal caso, es que se hace necesaria y urgente la crítica pública, decidida y honesta, para llamar la atención acerca de la situación y para intentar incidir en un cambio de rumbo. Popper es realista y sabe que la crítica pública no lo es todo:

El ejercicio público de la crítica, ciertamente, no lo es todo. En sí mismo, no puede resolver el conflicto de intereses o de ideales. Pero puede hacer que las partes en conflicto sean más conscientes unas de otras. Puede preparar a quienes no son más intolerantes para que se comprometan, y puede hacer que los demás sean más tolerantes. Y puede hacer que 'nosotros' influyamos en la política de quienes controlan las instituciones, siempre que nosotros nos interesemos suficientemente. ${ }^{37}$ 


\section{Reflexión final: democracia, crítica e intelectuales}

Hay que decir que cuando Popper habla de "nosotros" se refiere a los intelectuales y su responsabilidad moral. Más adelante se plantearán algunas ideas suyas al respecto. Antes, hay que dejar anotado que, para él, la democracia es impensable sin la crítica del poder. Esto fue así, nos recuerda, desde los orígenes mismos de la democracia en el siglo V antes de Cristo. Dos autores griegos son claves para entender la tesis de Popper según la cual la crítica es un sostén ineludible de la democracia. El primero es Pericles, cuya oración fúnebre es una pieza clave de las convicciones popperianas en el tema que nos ocupa.

Nuestra ciudad -dice Pericles- tiene las puertas abiertas al mundo; jamás expulsamos a un extranjero... somos libres de vivir a nuestro antojo y, no obstante, siempre estamos dispuestos a enfrentar cualquier peligro... amamos la belleza sin dejarnos llevar por fantasías, y si bien tratamos de perfeccionar nuestro intelecto, esto no debilita nuestra voluntad... Admitir la propia pobreza no tiene entre nosotros nada de vergonzoso; lo que consideramos vergonzoso es no hacer ningún esfuerzo por evitarla. El ciudadano ateniense no descuida los negocios públicos por atender sus asuntos privados... no consideramos inofensivos, sino inútiles, a aquellos que no se interesan por el Estado; y si bien sólo unos pocos pueden dar origen a una política, todos nosotros somos capaces de juzgarla. No consideramos la discusión como un obstáculo colocado en el camino de la acción política, sino como un preliminar indispensable para actuar prudentemente $^{38}$.

Juzgar la política, discutir sobre ella, examinar, con el uso de la razón, sus límites y debilidades: esa es la raíz de la crítica en la democracia. Se trata de una responsabilidad que los ciudadanos no pueden eludir; están obligados moralmente a hacerlo, pues en ello se juega su misma condición de personas libres, autónomas y racionales:

El miembro de una sociedad y ciudadano de un Estado libre -dice Poppertiene, sin lugar a dudas, un deber de lealtad hacia el Estado, porque la existencia del Estado es esencial para la persistencia de la sociedad... Y, sin embargo, es también su deber combinar con esta lealtad cierto grado de vigilancia, e incluso cierto grado de desconfianza respecto al Estado y sus funcionarios: su deber es velar y estar pendiente de que el Estado no exceda los límites de sus funciones legítimas, y allí donde hay poder siempre existe el peligro de que sea mal empleado. ${ }^{39}$

38. Pericles citado por K. R. Popper, La sociedad abierta y sus enemigos. Barcelona, Paidós, 1998, p. 182. El fragmento completo de la oración fúnebre de Pericles está recogido en Rafael del Águila, Fernando Vallespín y otros, La democracia en sus textos. Madrid, Alianza, 1998, pp. 32-37.

39. "La sociedad abierta y el Estado democrático (1963)", en Después de la sociedad abierta., p. 310. 
El autor al que se remite Popper para fundamentar su tesis es Sócrates, en quien se juntan tanto lo mejor de la moral de la responsabilidad individual como lo mejor de la responsabilidad ético-política. "[Sócrates] enseñó a tener fe en la razón pero, al mismo tiempo, a prevenirse del dogmatismo: a mantenernos apartados de la misología, la desconfianza en la teoría y en la razón, y de la actitud mágica de aquellos que hacen un ídolo de la sabiduría; y que enseñó, en suma, que el espíritu de la ciencia es la crítica”.40

El humanismo y la ética de Popper tienen su raíz en el humanismo y la ética de Sócrates. Las enseñanzas socráticas son una fuente de la visión ética y política de Popper:

...hemos mencionado ya -escribe- algunos aspectos de las enseñanzas socráticas: su intelectualismo, es decir, su teoría igualitaria de la razón humana como medio universal de comunicación; su insistencia en la honestidad intelectual y en la autocrítica; su teoría igualitaria de la justicia, y su doctrina de que es mejor ser víctima de una injusticia que cometerla con los demás. Es esta última doctrina, en mi opinión, la que mejor puede ayudarnos a comprender la médula misma de sus enseñanzas, de su credo individualista, de su creencia en el individuo humano como un fin en sí mismo. ${ }^{41}$

Creer en el individuo es creer en su responsabilidad; es creer en sus capacidades racionales y morales. Pero, claro está, el ejercicio de esa responsabilidad, del uso de la razón y de la propia autonomía, no es un regalo del cielo, sino algo que se hace valer en cada momento de la existencia. Nadie puede eludir ese desafío, a menos que decida renunciar a su humanidad y a su libertad:

Es este un problema que debemos encarar francamente, por duro que ello nos resulte. Si soñamos con retornar a nuestra infancia, si nos tienta el deseo de confiar en los demás y dejarnos ser felices, si eludimos el deber de llevar nuestra cruz, la cruz del humanitarismo, de la razón, de la responsabilidad, si nos sentimos desalentados y agobiados por el peso de nuestra carga, entonces debemos tratar de fortalecernos con la clara comprensión de la simple decisión que tenemos ante nosotros. Siempre nos quedará la posibilidad de regresar a las bestias. Pero si queremos seguir siendo humanos, entonces sólo habrá un camino, el de la sociedad abierta. Debemos proseguir hacia lo desconocido, lo incierto y lo inestable sirviéndonos de la razón de que podamos disponer, para procurarnos la seguridad y la libertad que aspiramos. ${ }^{42}$

40. La sociedad abierta y sus enemigos. Ibíd., p. 181.

41. Ibíd., p. 185.

42. Ibíd., p. 195. 
Los intelectuales tienen una enorme responsabilidad moral ante la sociedad. Deben ser conscientes, ante todo, de que su saber es limitado, es decir, que son falibles y que es más lo que no saben que lo que saben. Sin embargo, también tienen el deber de defender la capacidad del intelecto humano para aproximarse cada vez más a la verdad, siempre y cuando se haga un ejercicio crítico de la razón. Como cualquier persona, las decisiones morales del intelectual son responsabilidad suya, y, como cualquier persona, su guía debería ser su propia razón. Con todo, al intelectual más que a nadie, le corresponde defender un ejercicio crítico de la razón. Quizá esa sea su principal obligación moral. Los referentes intelectuales y morales de Popper en este punto son el racionalismo y la Ilustración, especialmente tal como asumieron Kant y Pestalozzi. En la formulación de Popper:

Podría expresarse la actitud racionalista de la siguiente manera: quizá yo no tengo razón y tú tienes razón; en todo caso, ambos podemos confiar en ver después de nuestra discusión algo más claro que antes, $y$ de todos modos ambos podemos aprender mutuamente, mientras no olvidemos que no se trata tanto de ver quién tiene la razón, sino mucho más de aproximarse a la verdad. Sólo con esta finalidad nos defendemos en la discusión tan bien como podemos.

Esto es, en pocas palabras, lo que quiero decir cuando hablo de racionalismo. Pero cuando hablo de la ilustración, me refiero todavía a algo más. Entonces pienso, sobre todo, en la idea de autoliberación por medio del saber -aquella idea que inspiró a Kant y a Pestalozzi-; y en el deber de cada intelectual de ayudar a los demás a liberarse espiritualmente y a entender la actitud crítica; un deber que han olvidado la mayoría de los intelectuales desde Fichte, Schelling y Hegel. Pues desgraciadamente está muy extendido entre los intelectuales el deseo de infundir respeto a los demás y, como dice Schopenhauer, no de ilustrarlos, sino de deslumbrarlos. Se presentan como guías, como profetas... Se buscan guías y profetas. No es de extrañar que se encuentren guías y profetas. Pero 'seres humanos adultos no necesitan ningún guía', como dijo una vez $\mathrm{H}$. G. Wells; y los adultos deberían saber que no necesitan ningún guía. Y por lo que al conjunto de profetas respecta, creo en el deber de cada intelectual de distanciarse de ellos por lo más inteligible. ${ }^{43}$

En definitiva, los intelectuales, si quieren contribuir a que la sociedad supere sus situaciones más graves para la vida de las personas, no deben -siguiendo las exigencias de la razón crítica y los valores ilustrados- abandonar la plaza pública, dejando que la sinrazón, el dogmatismo y los intereses mezquinos se impongan como criterios de convivencia social y política. A la manera de Sócrates, deben someterlo todo -incluida la democracia y sus supuestos- al

43. K. R. Popper, La responsabilidad de vivir. Escritos sobre política, historia y conocimiento. Barcelona, Paidós, 1994, p. 138. 
escrutinio de la crítica, pues en ello radica su contribución invaluable a la democracia. No hacerlo los convierte, como dice Popper siguiendo a Julien Benda ${ }^{44}$, en los "traidores del espíritu". Tal es lo que sucede cuando "queremos llamar la atención y hablamos un lenguaje incomprensible, pero sumamente espectacular, erudito, ingenioso, el cual hemos heredado de nuestros maestros hegelianos... Es esta contaminación lingüística la que hace precisamente imposible hablar razonablemente con nosotros, intelectuales, y pescamos en río revuelto". ${ }^{45}$ 